Varia 


\section{A 150 anos do Guarani: origens e destinos}

Maria Cecília Bruzzi Boechat | UFMG

Resumo: Análise de $\mathrm{O}$ guarani a partir da discussão do epilogo do romance. Breve comentário sobre $\mathrm{O}$ licenciado, de Pompílio Cavalcante de Moura, publicado na década de 50 do século XX, e que se apresenta como uma continuidade do romance de José de Alencar.

Palavras-chave: Romantismo brasileiro, O Guarani, O licenciado.

1.

A preservação de um dado muito interessante sobre O Guarani - o rumor que cercou a publicação do romance quanto aos motivos da escrita dos seus capítulos finais - nos é devida a uma longa tradição familiar que seria, depois, algumas vezes retomada por nossa tradição crítica.

Sobrinho do escritor, Araripe Júnior parece ter sido o primeiro a revelar, não sem admiração, que Alencar teria "dado o romance como acabado com a catástrofe em que desabou a casa de D. Antonio de Mariz", mas que, a pedido de suas irmãs, que liam a obra com o máximo interesse, permitiu escrever esse epílogo". ${ }^{1}$

1. ARARIPE JR., 1958, p. 167. 
Mais tarde, Raquel de Queirós, neta de D. Maria de Macedo Lima, prima-irmã de Alencar, apresentaria uma variante dessa versão:

Recordavam as primas os serões de leitura, durante os quais o romancista lia manuscritos inéditos para a família enlevada. O famoso caso do Guarani, tantas vezes repetido por minha bisavó Miliquinha, com quem ainda convivi (pois morreu aos 87 anos, em 1923) diz que na primeira cópia O guarani terminava por ocasião do incêndio com a morte de todo mundo, inclusive Peri e Ceci. Mas tal foi a mágoa das primas ouvindo a leitura do último capítulo, com tal pranto acolheram elas o destino trágico da donzela e do amante, e tais rogos fizeram ao autor para que os salvasse da desdita, que o "primo José" comoveu-se e prometeu um desenlace feliz, no qual se salvariam o índio e a moça loura. Daí a origem daquele final inesperado, a enchente do Paraíba, o desenraizar da palmeira e a salvação do casal (... $)^{2}$

Em meados do século XX, a história foi retomada por Brito Broca (1958) e por Cavalcanti Proença, que a consigna na primeira edição das obras completas de Alencar (1960), garantindo sua preservação em um momento de rara solenidade e simbolismo.

Nessa trajetória, o que muda não é tanto o episódio, que tem um ou outro detalhe alterado ou inserido, mas a sua recepção: enquanto Araripe Júnior e Raquel de Queirós vinham a público atestar a sua veracidade, Brito Broca e Cavalcanti Proença alertam para sua improbabilidade. Recorrendo a informações prestadas pelo próprio autor, em Como e porque sou romancista, ponderam, por um lado, que o tipo de composição do romance, publicado originalmente em folhetim, escrito, portanto, au jour le jour, não deixaria tempo para o luxo de uma "primeira cópia”. Ademais, Alencar dera a entender, nessa mesma obra, que, na época, residia sozinho na casa do largo do Rocio, que se encontrava em obras.

Ambos os estudiosos, então, refutam a versão familiar. "Considere-se, pois, como bem provado que as parentas leram O Guarani foi mesmo em letra de forma e que, lançada a versão da choradeira e das súplicas, não se perdeu tempo em verificar a verdade", conclui Cavalcanti Proença, na esteira de Brito Broca,

2. Apud BROCA, 1993, p. 91-92.

3. Trata-se da primeira edição da obra completa do escritor, e representa, para Mário de Alencar, "o monumento definitivo de sua glória". Apud COUTINHO. Nota Editorial. In: ALENCAR, 1960, v. 1, p. 9.

4. PROENÇA. José de Alencar na literatura brasileira. In: ALENCAR, 1960, v. 1 , p. 27. 
que, argumentando com os mesmos dados, se perguntava se o final adicionado não passaria de mais um dos "folclores de nossa vida literária".

A resolução do detalhe biográfico, entretanto, parece não ter esgotado o interesse do episódio. Folclore ou fato, resta ainda compreender por que a versão familiar pôde por tanto tempo ser preservada. Ou seja: o que se coloca em questão não é propriamente a falsidade do detalhe biográfico, mas a sua verossimilhança - verossimilhança que só pôde ser sustentada por um epílogo que se mostra efetivamente "falso" ou "artificial", de tal modo a criar a impressão de que tenha sido acrescentado a uma obra já acabada.

Significativamente, o aspecto mais discutido do romance tem sido justamente a sua parte final e sua relação com o restante da narrativa, constituindo o elemento que mais problemas e resistência apresentou para a compreensão crítica da obra.

A primeira questão que se apresenta é sobre a função do epílogo. Na versão familiar, ele viria reverter o sentido trágico da narrativa, como interpreta Raquel de Queirós. Segundo ela, “o 'primo José' comoveu-se e prometeu um desenlace feliz, no qual se salvariam o índio e a moça loura. Daí a origem daquele final inesperado, a enchente do Paraíba, o desenraizar da palmeira e a salvação do casal (...)", explica, claramente direcionando o romance para um desenlace harmonioso.

Ao retomar a versão, entretanto, Cavalcanti Proença, além de refutar sua veracidade, apresenta outra interpretação, insistindo na irresolução do romance: "Do autor não há depoimento", alerta, "sobre o porquê do final indeterminado de O guarani: Ceci e Peri descendo as águas na copa da palmeira, que a enchente leva para onde o leitor quiser: para a morte ou para o amor numa ilha edênica." ${ }^{6}$

Temos, assim, duas interpretações para o epílogo do romance, e, dependente delas, ou bem concluímos que o romance apresenta uma estrutura que, com ou sem razão, chamaríamos de tipicamente romântica (narrativa dos empecilhos encontrados para a realização do par amoroso, que ao final se une), aproximando-se das vertentes sentimentalistas do romance europeu, ou bem apresenta uma estrutura aberta, próxima das vertentes mais experimentalistas e reflexivas do Romantismo alemão.

5. Apud BROCA, 1993, p. 92.

6. PROENÇA. José de Alencar na literatura brasileira. In: ALENCAR, 1960, v. 1, p. 27. 
As conseqüências para uma leitura ideológica do romance são também significativas. Tendemos, em nossa recepção historiográfica e crítica do romance, a interpretá-lo como uma tentativa frustrada de afirmação de valores nacionalistas, uma vez que o desfecho do romance recairia em uma perspectiva colonialista, atrelada aos interesses do Império português. E, de fato, se direcionamos o epílogo para um desenlace feliz, os conflitos históricos explorados no decorrer da narrativa e que acabam por conduzir ao incêndio da casa de D. Mariz são subsumidas pelo epílogo harmonizador (a vitória do amor inter-racial de Ceci e Peri representando a vitória, ou o elogio, a uma política conservadoramente conciliatória).

Segundo essa leitura, o romance seria constituído por dois movimentos. A primeira parte estaria dedicada à configuração de uma situação harmônica (a convivência nos domínios de D. Mariz) que se desestabiliza (pela ação dos agregados e pelo ataque dos Aimorés), consistindo-se numa narrativa desilusória, por explorar os conflitos de interesses que levaram à derrocada do projeto colonizador de D. Mariz. No epílogo, entretanto, a narrativa passaria a empreender um segundo movimento, de re-harmonização, recompondo-se como narrativa de ilusões (o idílio amoroso, o mito de um amor edênico, de recomeço pós-diluviano), apagando, assim, as marcas do conflito de interesses que movimentam o enredo da primeira parte da narrativa.

A predileção, em nossa tradição historiográfico-crítica, por essa interpretação pode ser atestada por uma das mais recentes análises do romance, realizada por Valéria de Marco, que conclui:

O Guarani quer voltar às origens e propor outro caminho. Quer apagar os sinais de luta pela terra, de devastação da natureza, de trilha de tesouros, de extermínio do nativo, da prática do saque tão selvagem quanto os hábitos antropófagos de algumas tribos indígenas. O romance parece apontar os traços que deveriam talhar o perfil do país: extrair a riqueza do cultivo da terra e reconhecer a prática da conciliação como atributo e função fundamentais da autoridade. (...) E o tom conservador da voz de Alencar começa a esboçar-se nessa leitura dos tempos coloniais. Narrando um passado tão heróico que caminha para o mito, ele quer cicatrizar as fendas abertas pelos conflitos e quer, como a palmeira deslizando, inaugurar o horizonte histórico.?

7. DemarCO, 1993, p. 90-91. 
Se respeitamos, porém, o caráter aberto, indeterminado, do epílogo (tal como alertou Cavalcanti Proença), o sentido ideológico do romance tem de ser reconsiderado: recupera-se, então, uma ambigüidade que sugere uma narrativa muito mais desiludida, irônica ou crítica, uma representação menos eufórica e exaltadora do amor e da nação do que sempre quisemos acreditar. Ainda nessa perspectiva, é preciso reconsiderar a relação estabelecida entre o final e a narrativa que lhe antecede.

A conseqüência desse deslocamento que me parece fundamental é a abertura temporal do romance, que, assim poderemos ver, se joga para o futuro, e não para o passado: ora, se a aventura do par amoroso não tem desenlace definido, e se o destino dessas personagens representa, metaforicamente, o da nação brasileira, isso significa que os conflitos coloniais brasileiros não são encenados como um processo acabado. Que a utopia não tenha sido alcançada, nem sequer que o passado tenha sido harmônico parece ser justamente o que diz a suspensão da narrativa. Suspensão que mostra a resistência da narrativa tanto por optar por uma visão propriamente histórica quanto por uma mítica do processo colonizador brasileiro.

Invertendo, então, o raciocínio corrente sobre o romance: após termos considerado as brechas abertas na representação harmonizadora da colonização portuguesa pela representação dos conflitos históricos, mas que seriam "cicatrizadas" pelo final mítico, é preciso reconhecer, agora, as brechas abertas no mito pela própria consciência histórica do texto e em vigor em sua primeira parte.

Voltando às páginas do livro, visitemos as ruínas da casa do Paquequer, para ressaltar o registro do excesso de violência do último confronto, pois ainda vislumbramos, aqui e ali, "alguma índia, resto das tribos dos Aimorés, que tinha ficado para chorar a morte dos seus e para levar a notícia da tremenda vingança." Ao longe, vemos passar, na larga esteira do rio Paraíba, a forma vaga e indecisa da canoa de Peri, onde dorme ainda Ceci, sob efeito do sonífero aplicado por D. Mariz. Entre essa cena e a última, todo o epílogo se compõe em torno de um novo conflito: como tornar viável a vida amorosa do casal. Por um lado, a permanência de Ceci na selva tem de ser descartada, frente à promessa feita pelo índio a D. Mariz de levar a salvo a moça até a casa de parentes, no Rio de Janeiro. Por outro lado, mais de uma vez Ceci enuncia as dificuldades colocadas para o casal caso a opção fosse pela vida em sociedade, referindo-se aos preconceitos raciais e às conseqüências pessoalmente desastrosas para o indígena. Desse modo, estabelece-

8. ALENCAR. O guarani. In: ALENCAR, 1960, v. 2, p. 369. 
se a diferença evidente entre a utopia amorosa e as condições de sua realização no plano da realidade. Ou, em termos políticos: entre a utopia (ou o discurso) da conciliação e a historicidade (e realidade do presente) dos conflitos de interesses (do processo colonial, e, depois, da nação recém-independente).

Se mantida a inteireza do corpo narrativo de O Guarani, poderemos perceber que o epílogo, longe de apagar os conflitos da narrativa, os traz novamente à cena. Nessa perspectiva, a impossibilidade de realização amorosa do par Ceci e Peri pode ser percebida como uma reduplicação da história trágica do par Izabel (filha ilegítima de D. Mariz, descendente de mãe indígena) e Álvaro (cavalheiro português). Talvez nunca seja demais ressaltar a importância desse espelhamento, e do papel exercido por Izabel na narrativa: o de mestiça (representante, portanto, do povo brasileiro, que já aparece configurado antes do epílogo) sempre importunada e humilhada por D. Lauriana, esposa de D. Mariz, "dama paulista, imbuída de todos os prejuízos de fidalguia daquele tempo.” A posição e destino desta personagem constituem a contraversão do discurso da mestiçagem como processo harmonizador e formador do país, discurso que, paradoxalmente, vai sendo recomposto pelo narrador por meio da história de Ceci e Peri.

Por fim, cabe discutir o que, pessoalmente, sempre me intrigou no epílogo do romance: trata-se de uma incoerência na cena final, que nunca vi comentada antes na fortuna crítica (o que dá bem a medida da eficiência da técnica narrativa aí empregada). É preciso reler a última página do romance para recuperar o contraste evidente entre o que é narrado e o modo como é narrado:

Ela embebeu os olhos do seu amigo, e lânguida reclinou a loura fonte. O hálito de Peri bafejou-lhe a face.

Fez-se no semblante da virgem um ninho de castos rubores e lânguidos sorrisos: os lábios abriram como as asas purpúreas de um beijo soltando o vôo.

A palmeira arrastada pela torrente impetuosa fugia...

E sumiu-se no horizonte... ${ }^{10}$

A cena é ágil e tumultuosa: focaliza Ceci e Peri, fragilmente equilibrados num tronco de palmeira, que é arrastada pela torrente impetuosa. Momento de plena ação e suspense. Em contraste com o dinamismo da cena, o narrador imprime

9. ALENCAR, José de. O guarani. In: ALENCAR, 1960, v. 2, p. 39.

10. ALENCAR. O guarani. In: ALENCAR, 1960, v. 2, p. 399. 
tranqüilidade: calmamente, recorre por duas vezes às reticências (sugerindo continuidade, no momento mesmo em que o desastre se apresenta iminente). Note-se, ainda, o uso, também por duas vezes, em tão curto trecho, e para descrever uma cena de tanta velocidade, do adjetivo "lânguida."

Muito evidentemente, se desse modo o escritor acalma a parentada, teimosamente insiste em reiterar o caráter conflituoso do enredo do romance, criando, ao mesmo tempo, uma ilusão e uma desilusão (a ambigüidade do final). Nesta perspectiva, o epílogo não constituiria uma inversão da primeira narrativa, mas sua duplicação: espécie de espelho interno de que se dota a narrativa para recuperar o caráter problemático do romance. Se a narrativa sofre uma inflexão, pela possibilidade aberta para a interpretação harmonizadora, não sofre, porém, reversão: o que estava traçado, no passado (o destino trágico de Izabel e Álvaro e, por outro lado, a derrocada do projeto de D. Mariz) abre-se para o futuro, que pode ou não mudar o sentido histórico do processo civilizatório brasileiro.

Como se pode depreender, não se trata, de fato, de uma crítica em bloco (mas tampouco de aderência) ao projeto português, mas da afirmação de seu caráter problemático e dos limites de um discurso conciliatório que, tal como no romance, não é capaz de dissolver ou "apagar" conflitos históricos, do passado ou do presente.

Há muito que se reconsiderar, então, na imagem de um Alencar passadista, de um romantismo selvagem, pré-social, tanto quanto na de um escritor inábil na finalização de seus romances. "José de Alencar tinha esse defeito", advertira Araripe Júnior: "Facilitava muito as soluções nas últimas páginas de seus livros. Facilitava muito: a 150 anos da publicação de O Guarani, talvez já seja hora de desconfiar do modo não só evidente, como recorrente, da "artificialidade", da "falsidade" de seus finais harmonizadores, e, enfim, reconhecê-los como um artifício...

11. Note-se que a mesma estratégia fora usada em Iracema: também nesse romance, a voz harmonizadora do narrador entra em contradição com as ações das personagens e os conflitos explorados no enredo. Sem avançar muito na análise, atente-se para a dissonância entre o reconhecidamente caráter "épico" do romance e o "tom poético" da narrativa.

12. ARARIPE Jr., 1958, v. I, p. 184. 


\section{2.}

Argumentações à parte, uma evidência inegável do caráter aberto do romance já foi fornecida pelo próprio sistema literário brasileiro. Brito Broca assinala a existência da publicação de uma "continuação" de O Guarani, editada, em 1954, pela Livraria Progresso da Bahia, assinada com as iniciais P.C.M. e provavelmente escrita depois de 1877 (quando Alencar já havia morrido). A autoria já foi devidamente reconhecida na edição de 1954, que revelou tratar-se de Pompílio Cavalcante de Moura, do qual Brito Broca, como nós, jamais ouvira falar. ${ }^{13}$

Tive acesso a um volume desse romance, hoje praticamente desconhecido, exclusivamente graças à gentileza e reconhecida generosidade do colega da Faculdade de Letras da UFMG, o Professor José Américo de Miranda. No Prefácio, os editores retomam a versão familiar sobre o acréscimo do final de O Guarani e esclarecem o sentido dado à narrativa por sua retomada ficcional:

Conta-se que a própria família do escritor reunia-se para a leitura do folhetim diário, e que no seu seio combatia-se a sua idéia de fazer morrerem todos os heróis do romance, dando-lhe um desfecho trágico.

Talvez por isso, o desfecho do romance se tenha modificado, deixando Alencar suspensa uma interrogação sobre o fim de Ceci e Peri, acenando, através dessa dúvida, com a esperança de um destino para além das águas revoltas do Paquequer em cheia.

Foi talvez para responder a esta interrogação e para realizar esta esperança, que Pompílio Cavalcante de Moura[...] publicou 'O Licenciado', onde procurou dar uma seqüência lógica aos acontecimentos do livro, para conduzi-los ao clássico "final feliz".

Os próprios editores, porém, são os primeiros a reconhecer a falta de qualidade literária dessa continuação (censurando-lhe "a linguagem demasiadamente preciosa, a inverossimilhança chocante das cenas, a impropriedade de expressões, a completa falta de coerência, de espírito de observação, as falhas mesmo elementares de uma boa composição gramatical"), mas insistindo em que o livrinho vinha a atender "àquela insatisfeita indagação do fim de Ceci e Peri."

13. BROCA, 1979, p. 284.

14. Prefácio (dos editores). In: MOURA, 1954, p. 6.

15. Do mesmo prefácio, p. 7. 
Em seu comentário ao texto, Brito Broca retoma as censuras dos editores e ressalta, ademais, a inverossimilhança da continuidade dada à personagem de Peri, transformado no "licenciado" a que se refere o título. Para compreender sua crítica, acompanhemos, antes, o resumo da narrativa:

E qual a idéia do autor? Por iniciativa de Dom Diogo, irmão de Ceci, Peri, graças ao ouro que descobrira numa mina, vai estudar Medicina em Coimbra, para poder casar-se com Ceci. Depois de formado, percorre vários países da Europa passando por Paris, onde manda confeccionar o enxoval. De novo no Brasil, casa-se e vai, em companhia da linda esposa, jornadear em viagem de núpcias pelo Velho Mundo, ficando a residir, finalmente, numa suntuosa vivenda senhorial, em Lisboa.

Daí, a conclusão:

Nabuco acusou Alencar de ter feito de Peri um índio efeminado, que, de forma alguma, corresponde à realidade étnica do tipo. Peri é um Amadis de Gaula das selvas brasileiras. Mas o Peri de Pompílio Cavalcante de Moura incorre numa inverossimilhança que toca às raias do ridículo. Parece mais o herói de Romance de um Moço Pobre do que um índio.

Ridículo, de fato: o encaminhamento ao "final feliz" tem como efeito o completo apagamento da ambigüidade do herói do romance de Alencar e que é mantida pelo final em aberto do romance. Pois, se o Peri de Alencar possui as virtudes de um cavalheiro, ele mantém, sempre, alguma distância do mundo civilizado. Sua função, no romance de Alencar, é justamente a de funcionar como uma espécie de ponte entre o mundo selvagem (representado pelos Aimorés) e o mundo de D. Mariz: é índio, mas um índio apenas potencialmente capaz de ser integrado ao projeto civilizatório brasileiro. O que o "final feliz" nega e retira do romance é a problematização desse projeto, realizada pela encenação dos conflitos de interesses (colonizadores-índios; brancos-mestiços) e reafirmada justamente pela resistência do romance ao encaminhamento harmonizador.

É o que parece perceber também Brito Broca, que, por sua vez, não resiste a dar uma versão alternativa para uma "continuação" do romance, explorando outra vertente aberta pela indeterminação causada por seu epílogo:

16. BROCA, 1979, p. 286. 
[...] a idéia de uma continuação de O Guarani prestar-se-ia a um romance bem curioso e com certo fundo social. Imaginasse o escritor Peri, acompanhando Cecília, quando esta retornasse para junto dos irmãos e dos tios no Rio de Janeiro, depois de salva da inundação pelo índio. Permaneceria ele fiel por muito tempo, nesse meio civilizado, à criatura amada, até que acabaria por sentir, absorvente, a nostalgia da selva. Então, cansado de adorar aquela mulher,que jamais poderia ser sua esposa,regressa à taba dos Goitacazes. Mas já tendo alguma experiência da civilização, não consegue readaptar-se ao ambiente selvagem. Daí tornar-se um marginal,no sentido sociológico da palavra - conflito que um romancista hábil saberia tirar melhor proveito. ${ }^{17}$

Apenas imaginada, e de todo modo, também desviante em relação à vontade do próprio autor, que intencionalmente deixa em aberto o destino de suas personagens, a proposta de Brito Broca soa, sem dúvida, mais verossímil, pelo motivo muito óbvio de que o destino histórico do processo colonizador brasileiro já era, então (1958), conhecido. Frustras as expectativas utópicas de Alencar, a vertente pessimista do romance foi a que se viu confirmada pela realidade histórica.

Que se mantenha em vista, entretanto, que, se ambas as versões foram possíveis (e ambas são "corretas"), é porque o romance original de fato contém, em si, as duas perspectivas - e nossa interpretação de O Guarani não deveria apagar nenhuma delas: nem sua representação problematizadora do passado e do presente histórico do escritor, nem sua expectativa utópica por um futuro menos conflituoso e mais harmônico.

Résumé: Analyse de $\mathrm{O}$ guarani à partir de la discussion de l'épilogue du roman. Bref commentaire sur $\mathrm{O}$ licenciado, de Pompilio Cavalcante de Moura, publié au siècle XX dans la décennie de 50, et qui se présente comme une continuation du roman de José de Alencar.

Mots-clés: Romantisme brésilien, O Guarani, O licenciado.

17. BROCA, 1979, p. 287. 


\section{Referências Bibliográficas}

ALENCAR, José de. O guarani. In: Obra completa. Rio de Janeiro: Aguilar, 1960. v. 2. ARARIPE JR. José de Alencar: perfil literário. In: Obra crítica. v. 1. São Paulo: Casa de Rui Barbosa, 1958. v. 1.

BROCA, Brito. Convite a uma pesquisa: verdade ou folclore? In: Escrita e vivência. Campinas: Ed. da Unicamp, 1993.

BROCA, Brito. Uma continuação de O Guarani. In: Românticos, Pré-Românticos e Ultra-Românticos. São Paulo: Polis, 1979.

COUTINHO. Nota Editorial. In: ALENCAR, José. Obra completa. Rio de Janeiro: José Aguilar, 1960. v. 1.

DeMARCO, Valéria. A perda das ilusões: o romance histórico de José de Alencar. Campinas: Ed. da Unicamp, 1993.

MOURA, Pompílio Cavalcante de. Prefácio (dos editores). In: O Licenciado: continuação de O Guarani. Salvador: Livraria Progresso, 1954.

PROENÇA. José de Alencar na literatura brasileira. In: ALENCAR, José de. Obra completa. Rio de Janeiro: José Aguilar, 1960. v. 1. 